\title{
Risk Aversion at the Country Level
}

Néstor Gandelman and Rubén Hernández-Murillo

This article estimates the coefficient of relative risk aversion for 75 countries using data on self-reports of personal well-being from the 2006 Gallup World Poll. The analysis suggests that the coefficient of relative risk aversion varies closely around 1 , which corresponds to a logarithmic utility function. The authors conclude that their results support the use of the log utility function in numerical simulations of economic models. (JEL D80, D31, I31, O57)

Federal Reserve Bank of St. Louis Review, First Quarter 2015, 97(1), pp. 53-66.

A $\mathrm{n}$ individual's attitude about risk underlies economic decisions about the optimal amount of retirement or precautionary savings to set aside, investment in human capital, public or private sector employment, and entrepreneurship, among other things. In the aggregate, these micro-level decisions can influence a country's growth and development.

Although there is a vast literature on measuring risk aversion, estimates of the coefficient of relative risk aversion vary widely-from as low as 0.2 to 10 and higher. Probably the most widely accepted measures lie between 1 and $3 .^{1}$ The most common approach to measuring risk aversion is based on a consumption-based capital asset pricing model (CAPM). Hansen and Singleton (1982), using the generalized method of moments (GMM) to estimate a CAPM, report that relative risk aversion is small. Hall (1988) shows that minor changes in the specification and instruments cause the results to vary substantially. Neely, Roy, and Whiteman (2001), in turn, explain this difference, arguing that CAPM-based estimations fail to provide robust results because difficulties in predicting consumption growth and asset returns from available instruments lead to a near identification failure of the model. In this article, we follow a different approach.

We build on the methodology first outlined in Layard, Mayraz, and Nickell (2008). Using happiness data to estimate how fast the marginal utility of income declines as income increases,

Néstor Gandelman is a professor of economics at Universidad ORT Uruguay. Rubén Hernández-Murillo is a senior economist at the Federal Reserve Bank of St. Louis. The authors thank the Inter-American Development Bank (IADB) and the Gallup Organization for facilitating access to the Gallup World Poll data. Christopher J. Martinek provided research assistance.

() 2015, The Federal Reserve Bank of St. Louis. The views expressed in this article are those of the author(s) and do not necessarily reflect the views of the Federal Reserve System, the Board of Governors, or the regional Federal Reserve Banks. Articles may be reprinted, reproduced, published, distributed, displayed, and transmitted in their entirety if copyright notice, author name(s), and full citation are included. Abstracts, synopses, and other derivative works may be made only with prior written permission of the Federal Reserve Bank of St. Louis. 


\section{Gandelman and Hernández-Murillo}

they use an iterated maximum likelihood procedure that assumes a constant relative risk aversion (CRRA) utility function. Under this assumption, the elasticity of the marginal utility of income corresponds to the parameter of relative risk aversion. In Gandelman and HernándezMurillo (2013), we also used this methodology to estimate the coefficient of relative risk aversion using pooled data from cross-sectional and panel datasets. Instead of maximum likelihood, in this article we use the GMM to perform the estimation. As with maximum likelihood, the GMM provides consistent and asymptotically normal estimates, but it does not rely on the normality assumption. Using the GMM also provides asymptotically correct standard errors for the coefficient of relative risk aversion, whereas the iterated maximum-likelihood procedure used in Layard, Mayraz, and Nickell (2008) and Gandelman and Hernández-Murillo (2013) does not easily provide a measure of the standard error for the parameter of interest.

The CRRA utility function is often used in applied theory and empirical work because of its tractability and appealing implications. ${ }^{2}$ Assuming a CRRA form for the utility function, nevertheless, has been criticized. For example, Geweke (2001) warns about the potential limitations of assuming a CRRA utility function for traditional growth models. He argues that, under this assumption, the existence of expected utility, and hence of an operational theory of choice, depends on distributional assumptions about macroeconomic variables and about prior information that do not necessarily hold. Because many distributions are difficult to distinguish econometrically, these assumptions may lead to widely different implications for choice under uncertainty. Another potential limitation is that, in dynamic models with a CRRA per-period utility function with time-separable preferences, the coefficient of relative risk aversion is also the reciprocal of the elasticity of intertemporal substitution (EIS). Epstein and Zin $(1989,1991)$ address this issue with a generalization of the standard preferences in a recursive representation in which current utility is a constant elasticity function of current consumption and future utility. This more-flexible representation of utility allows for differentiation between the coefficient of relative risk aversion and the EIS and is useful for explaining problematic aspects of asset pricing behavior. ${ }^{3}$ We acknowledge these criticisms, but we follow the happiness literature in assuming a CRRA form for the utility function because it provides a straightforward framework that can be used to estimate a measure of risk aversion summarized in a single parameter. This simple form is particularly useful when, as is our case, the only available data are cross-sectional observations on subjective well-being and income.

In estimating risk aversion, the literature has focused almost exclusively on developed countries. ${ }^{4}$ Moreover, with the exception of Szpiro (1986) and Szpiro and Outreville (1988), to the best of our knowledge no additional study has yet applied a homogenous methodology for estimating risk aversion for a large set of both high- and low-income countries. Szpiro (1986) initially used property/liability insurance data to estimate relative risk aversion for 15 developed countries. Szpiro and Outreville (1988) augmented the analysis to 31 countries, including 11 developing countries. Gandelman and Porzecanski (2013) use a slightly different approach. They apply different assumptions about relative risk aversion to a sample of 117 developing and developed countries from the Gallup World Poll to calibrate how much happiness inequality is due to income inequality. 
In this article, we fill this gap in the literature by eliciting risk-aversion measures for 75 countries, including 52 developing countries, from self-reports of personal well-being from the 2006 Gallup World Poll. This study is important for several reasons. First, applying the same methodology to different countries is useful for assessing the robustness of the estimates. Second, the study is a starting point for further research of cross-country differences in risk aversion and their correlation with multiple variables of interest. Third, dynamic stochastic general equilibrium models often rely on calibrated estimates of risk aversion for developed countries, usually without measures of the relevant parameters for developing countries. This study includes developing countries.

Our estimates show that individual country estimates of relative risk aversion vary between 0 (implying a linear utility function) and 3 (implying more risk aversion than log utility). We construct Wald tests for the null hypotheses that the coefficient of relative risk aversion equals 0,1 , or 2: 0 indicates a linear utility function in terms of income; 1 indicates a logarithmic utility function; and 2 corresponds to a value often used in the literature, which indicates a higher degree of concavity. ${ }^{5}$ Our sample includes 23 developed countries and 52 developing countries. Detailed outcomes of the hypothesis tests for the coefficients in both developed and developing countries are presented in the Results section. In brief, we reject the null hypothesis that the coefficient of relative risk aversion equals 1 in only 2 of the 23 developed countries and only 10 of the 52 developing countries. We reject that it equals 0 or 2 for most developed countries and many developing countries. Furthermore, an analysis of the distribution of the estimates indicates that for both developed and developing countries, most of the estimates are concentrated in the vicinity of 1 . We conclude that this result supports the use of the log utility function in numerical simulations.

\section{DATA}

The main variables of interest in the Gallup World Poll are self-reports of (i) satisfaction with life and (ii) household income. ${ }^{6}$ We also use the following individual control variables: age, gender, marital status, employment status, and residence in urban areas.

The self-reports of well-being from the Gallup World Poll are answers to the following question: Please imagine a ladder/mountain with steps numbered from zero at the bottom to ten at the top. Suppose we say that the top of the ladder/mountain represents the best possible life for you and the bottom of the ladder/mountain represents the worst possible life for you. If the top step is 10 and the bottom step is 0 , on which step of the ladder/mountain do you feel you personally stand at the present time? Henceforth, we do not distinguish well-being from happiness.

Table 1 reports summary statistics for the key variables in our estimations: the happiness scores, household income, and the control variables. The data for the 75 countries include 40,655 individual observations. The sample is split into developed countries (23) and developing countries (52) following the World Bank criterion: A country is defined as developing if its gross national income per capita is less than $\$ 12,000$ U.S. dollars in 2010.7

Table 1 shows summary statistics of the data for all the countries and for the countries divided into the two groups. On a scale of 0 to 10 , the means of average reported happiness were 5.5 for the overall sample, 6.7 for developed countries, and 4.9 for developing countries. ${ }^{8}$ In terms of the control variables, the overall sample includes individuals with an average age 


\section{Table 1}

\section{Summary Statistics}

\begin{tabular}{|c|c|c|c|c|c|c|c|c|c|c|c|c|}
\hline \multirow[b]{2}{*}{ Variable } & \multicolumn{4}{|c|}{ All countries $(N=75)$} & \multicolumn{4}{|c|}{ Developed countries $(n=23)$} & \multicolumn{4}{|c|}{ Developing countries $(n=52)$} \\
\hline & Mean & SD & Min. & Max. & Mean & SD & Min. & Max. & Mean & SD & Min. & Max. \\
\hline No. obs. & 542 & 150 & 230 & 1,241 & 552 & 95 & 418 & 867 & 538 & 170 & 230 & 1,241 \\
\hline Happiness & 5.5 & 1.2 & 3.4 & 7.8 & 6.7 & 0.8 & 5.3 & 7.8 & 4.9 & 0.8 & 3.4 & 7.2 \\
\hline Income (\%) & 92.3 & 8.6 & 47.1 & 109.8 & 97.8 & 3.5 & 91.0 & 101.7 & 89.9 & 9.1 & 47.1 & 109.8 \\
\hline Age (yr) & 42.4 & 2.8 & 36.3 & 47.7 & 44.7 & 1.5 & 42.0 & 47.7 & 41.3 & 2.7 & 36.3 & 46.9 \\
\hline Female (\%) & 55.6 & 6.4 & 42.4 & 72.2 & 58.0 & 6.1 & 49.3 & 72.2 & 54.5 & 6.4 & 42.4 & 69.2 \\
\hline Married (\%) & 69.1 & 10.0 & 36.2 & 90.2 & 68.9 & 6.5 & 55.6 & 82.8 & 69.3 & 11.2 & 36.2 & 90.2 \\
\hline Urban (\%) & 44.6 & 19.2 & 5.0 & 87.4 & 42.9 & 15.0 & 24.6 & 75.8 & 45.3 & 20.9 & 5.0 & 87.4 \\
\hline Employed (\%) & 59.9 & 14.0 & 23.7 & 88.3 & 71.6 & 9.4 & 52.6 & 88.3 & 54.7 & 12.6 & 23.7 & 86.9 \\
\hline
\end{tabular}

NOTE: Developed countries are those with gross national income per capita greater than $\$ 12,000$ USD in 2010 . Statistics are the country averages of the variable. Income is expressed relative to the country average. The mean does not equal 100 percent because outlier observations were trimmed. No. obs., number of observations; SD, standard deviation.

of 42.4 years, with slightly more women (55.6 percent) than men ( 44.4 percent), more married (69.1 percent) than single (30.9 percent), less than half (44.6 percent) living in an urban area, and over half (59.9 percent) employed. Comparing the samples for the developed and developing countries, the average age of the adults in the developed countries is older ( 44.7 years old vs. 41.3 years old), with a slightly larger percentage of women ( 58.0 percent vs. 54.5 percent) and a significantly higher percentage employed (71.6 percent vs. 54.7 percent). Both include about the same percentages of married individuals (around 69.0 percent), while slightly more individuals live in urban areas in developing countries than in developed countries (45.3 percent vs. 42.9 percent).

\section{ESTIMATION}

To perform the estimation we make several assumptions. First, we assume a CRRA form for the utility function. Second, because consumption data are not available, we assume that the utility function can be expressed in terms of income. Furthermore, because the measure of income typically available in happiness surveys (including the Gallop World Poll) is current household income, as opposed to permanent individual income, the utility function we estimate represents per-period utility instead of lifetime utility. Finally, because we are using selfreports of well-being as a proxy for utility, we make assumptions about the comparability of the responses across individuals.

\section{Utility Function}

We assume that an individual's experienced utility, $u$, can be explained, in addition to income, $y$, by a (row) vector of individual characteristics $\mathrm{x}$ via the function $U: \mathcal{u}=U(y, \mathrm{x})$. We 
assume that the relation $U$ is common to all individuals in a given country and is of the following form:

$$
u=U(y, \mathrm{x})=\alpha+\gamma g(y)+\mathrm{x} \beta,
$$

where $\alpha$ and $\gamma$ are scalars, $\beta$ is a column vector of the coefficients for the controls $\mathrm{x}$, and $g$ is a CRRA utility function for the relation with income

$$
g(y)=\left\{\begin{array}{l}
\frac{y^{1-\rho}-1}{1-\rho} \text { if } \rho \neq 1, \\
\log (y) \text { if } \rho=1,
\end{array}\right.
$$

where $\rho$ corresponds to the Arrow-Pratt coefficient of relative risk aversion. According to this specification, income enters the utility function as a proxy for consumption. In other words, this specification assumes that the effect of income on reported happiness corresponds to the causal effects of consumption on utility. While we follow previous studies in making this assumption, we recognize that it is not trivial and acknowledge its potential limitations. ${ }^{9}$

We also assume that reported happiness, $h$, is linked to experienced utility via a monotonically increasing function $f: h=f(u) .{ }^{10}$ For simplicity, as in most of the literature, we assume that the relation $f$ is common to all individuals. Furthermore, we assume that reported happiness scores are cardinally comparable across individuals, which implies that the relation $f$ is linear. The cardinality assumption justifies the estimation with ordinary least squares (OLS) as in Layard, Mayraz, and Nickell (2008) and Gandelman and Hernández-Murillo (2013). Alternatively, assuming that happiness scores are ordinally comparable would justify the estimation with ordered probit or ordered logit. Ferrer-i-Carbonell and Frijters (2004) report that the results from either assumption are indistinguishable in most studies using cross-sectional datasets, and since OLS estimates are easier to interpret, this method is often preferred. The results may differ when using panel data, however, if time-invariant effects are important. Therefore, Ferrer-i-Carbonell and Frijters (2004) argue that one can practically assume that happiness scores are interpersonally comparable both cardinally and ordinally.

Layard, Mayraz, and Nickell (2008) studied the implications of relaxing the linearity assumption on $f$. They were concerned especially that the bounded happiness scale would induce compression of the responses, particularly at the top of the scale. The authors found a small degree of concavity near the top of the scale, which implies that the estimate of the coefficient of interest may be biased upward under the linearity assumption. However, the authors determined that relaxing the linearity assumption had only a small effect on their conclusions, and therefore we maintain this assumption in our exercise.

\section{Estimation: Happiness and Utility}

The estimated equation for a representative country is therefore

$$
h_{i}=\alpha+\gamma g\left(y_{i}\right)+\mathrm{x}_{i} \beta,+v_{i},
$$




\section{Gandelman and Hernández-Murillo}

where $i=1, \ldots, n$ indexes individuals, $h_{i}$ is the index of reported happiness (on a 0 to 10 scale), and $v_{i}$ represents an error term that is independent of experienced utility, $u_{i}{ }^{11}$

We estimate the model with the GMM. Stacking the individual observations and letting $\mathrm{h}=\left(h_{1}, h_{2}, \ldots, h_{n}\right)^{\prime}$, the estimated equation is a nonlinear vector-valued function $H: R^{K+3} \rightarrow R^{n}$, of the parameters $=\left(\alpha, \gamma, \rho, \beta^{\prime}\right)^{\prime}, \mathrm{h}=H(\theta)$, where $\beta$ is a $(K \times 1)$ vector of coefficients for the control variables $\mathrm{x}_{i}$. Because of the CRRA assumption, we have more parameters than independent variables, so we need an appropriate set of instruments to conduct the estimation. Following Stewart (2011), we construct the set of instruments taking advantage of the nonlinearity of the specification as $Z=[\mathrm{J}(\theta), \mathrm{X}] .{ }^{12} \mathrm{~J}(\theta)$ is the $n \times(K+3)$ Jacobian matrix of first derivatives of the function $H$ with respect to the parameter vector $\theta$, where each row corresponds to the vector $\left(1, g\left(y_{i}\right), \gamma m\left(y_{i}\right), \mathrm{x}_{i}\right)$, where $m\left(y_{i}\right)=\frac{\partial g\left(y_{i}\right)}{\partial \rho}$, and $\mathrm{X}$ is the $n \times(K+2)$ data matrix, where each row corresponds to the vector $\left(1, y_{i}, x_{i}\right)$. Therefore, the matrix of instruments $\mathrm{Z}$ simplifies to a matrix with the following characteristic row: $\mathrm{z}_{i}=\left(1, g\left(y_{i}\right), \gamma m\left(y_{i}\right), y_{i}, \mathrm{x}_{i}\right){ }^{13}$

\section{RESULTS}

Table 2 reports the estimates of the relative risk aversion coefficient for the 75 countries in our sample. ${ }^{14}$ The estimates range between 0 and 3 . The median and simple averages of the country estimates are 0.94 and 0.98 , respectively. The average coefficient among developed countries is 0.92 , while that among developing countries is 1.00 . For each country we report Wald tests of the null hypotheses that the coefficient of relative risk aversion equals 0,1 , or 2 . The null hypothesis that $\rho$ equals 0 is rejected at the 10 percent level in 13 of the 23 developed countries and 34 of the 52 developing countries. In turn, the null hypothesis that $\rho$ equals 1 is rejected at the 10 percent level in 2 developed countries and 10 developing countries. Finally, the null hypothesis that $\rho$ equals 2 is rejected at the 10 percent level in 17 developed countries and 36 developing countries.

Figures 1 and 2 present the individual country estimates of the coefficient of relative risk aversion for developed and developing countries, respectively. The plots include 90 percent confidence intervals. The plots again indicate that, for most of the estimates in the middle of the distribution, we cannot reject that the coefficient is equal to 1. As shown in Figure 3, this conclusion is confirmed by a plot of the kernel density estimators, which indicates that most of the estimates for both the developed and developing countries are concentrated in the vicinity of 1 . In addition, the distribution of the estimates for the developed countries seems to contain relatively more observations between 0 and 0.5 , whereas that for the developing countries seems to contain relatively more observations around 2 . 


\section{Table 2A}

\section{Relative Risk Aversion by Country (Developed Countries)}

\begin{tabular}{|c|c|c|c|c|c|c|}
\hline & Country & $\rho$ & $\begin{array}{c}\chi^{2} \\
H_{0}: \stackrel{\rho}{\rho}=0\end{array}$ & $\begin{array}{c}\chi^{2} \\
H_{0}: \stackrel{\rho}{\rho}=1\end{array}$ & $\begin{array}{c}\chi^{2} \\
H_{0}: \rho=2\end{array}$ & No. obs. \\
\hline 1 & Australia & 1.17 & $21.86^{*}$ & 0.47 & $10.93^{*}$ & 594 \\
\hline 2 & Austria & 1.08 & $2.84^{*}$ & 0.02 & 2.03 & 465 \\
\hline 3 & Belgium & 1.55 & $7.20^{*}$ & 0.92 & 0.59 & 533 \\
\hline 4 & Canada & 0.83 & $7.01^{*}$ & 0.31 & $14.12^{*}$ & 867 \\
\hline 5 & Croatia & 0.31 & 0.23 & 1.16 & $6.92^{*}$ & 489 \\
\hline 6 & Estonia & 0.51 & 1.70 & 1.58 & $14.56^{*}$ & 488 \\
\hline 7 & Finland & 0.57 & 1.22 & 0.70 & $7.73^{*}$ & 433 \\
\hline 8 & France & 1.43 & 2.08 & 0.19 & 0.33 & 490 \\
\hline 9 & Germany & 0.77 & $6.06^{*}$ & 0.53 & $15.35^{*}$ & 630 \\
\hline 10 & Greece & 1.08 & $6.32^{*}$ & 0.03 & $4.61^{*}$ & 555 \\
\hline 11 & Ireland & 0.35 & 0.27 & 0.91 & $5.87^{*}$ & 443 \\
\hline 12 & Japan & 0.44 & 1.19 & 1.85 & $14.55^{*}$ & 550 \\
\hline 13 & Korea & 0.27 & 0.61 & $4.53^{*}$ & $25.38^{*}$ & 604 \\
\hline 14 & Netherlands & 0.10 & 0.02 & 1.36 & $6.08^{*}$ & 531 \\
\hline 15 & New Zealand & 1.15 & $8.75^{*}$ & 0.16 & $4.70^{*}$ & 565 \\
\hline 16 & Norway & 1.16 & 2.29 & 0.05 & 1.18 & 647 \\
\hline 17 & Poland & 0.38 & 0.62 & 1.62 & $11.11^{*}$ & 513 \\
\hline 18 & Portugal & 1.07 & $9.91 *$ & 0.04 & $7.44^{*}$ & 418 \\
\hline 19 & Slovenia & 0.83 & $7.49 *$ & 0.33 & $15.07^{*}$ & 527 \\
\hline 20 & Switzerland & 1.21 & $3.69^{*}$ & 0.11 & 1.59 & 528 \\
\hline 21 & Taiwan & 2.45 & $16.88^{*}$ & $5.91^{*}$ & 0.57 & 566 \\
\hline 22 & United Kingdom & 1.03 & $17.71^{*}$ & 0.01 & $15.85^{*}$ & 640 \\
\hline 23 & United States & 1.39 & $18.85^{*}$ & 1.48 & $3.64^{*}$ & 610 \\
\hline
\end{tabular}

NOTE: Developed countries are those with gross national income per capita greater than $\$ 12,000$ USD in 2010 . The chi-square statistics correspond to the likelihood ratio tests for the null hypotheses that $\rho=0, \rho=1$, or $\rho=2$. * indicates statistical significance at the 10 percent level. No. obs., number of observations. 
Table 2B

Relative Risk Aversion by Country (Developing Countries)

\begin{tabular}{|c|c|c|c|c|c|c|}
\hline & Country & $\rho$ & $\begin{array}{c}\chi^{2} \\
H_{0}: \rho=0\end{array}$ & $\begin{array}{c}\chi^{2} \\
H_{0}: \rho=1\end{array}$ & $\begin{array}{c}\chi^{2} \\
H_{0}: \rho=2\end{array}$ & No. obs. \\
\hline 1 & Albania & 0.14 & 0.24 & $8.73^{*}$ & $40.90^{*}$ & 453 \\
\hline 2 & Argentina & 1.20 & $4.03^{*}$ & 0.11 & 1.78 & 410 \\
\hline 3 & Armenia & 0.57 & 2.12 & 1.21 & $13.38^{*}$ & 520 \\
\hline 4 & Azerbaijan & 1.85 & $15.97^{*}$ & $3.37^{*}$ & 0.10 & 565 \\
\hline 5 & Bangladesh & 1.30 & $11.51^{*}$ & 0.61 & $3.34^{*}$ & 661 \\
\hline 6 & Belarus & 0.09 & 0.02 & 1.66 & $7.28^{*}$ & 528 \\
\hline 7 & Benin & 0.21 & 0.30 & $4.49 *$ & $22.91^{*}$ & 467 \\
\hline 8 & Bolivia & 0.16 & 0.16 & $4.63^{*}$ & $22.10^{*}$ & 450 \\
\hline 9 & Bosnia \& Herzegovina & 0.72 & $6.84^{*}$ & 1.03 & $21.60^{*}$ & 889 \\
\hline 10 & Botswana & 0.94 & $29.44^{*}$ & 0.12 & $37.55^{*}$ & 453 \\
\hline 11 & Brazil & 0.63 & 0.33 & 0.11 & 1.52 & 612 \\
\hline 12 & Bulgaria & 1.06 & $14.58^{*}$ & 0.04 & $11.53^{*}$ & 466 \\
\hline 13 & Burundi & 2.17 & $4.06^{*}$ & 1.18 & 0.02 & 451 \\
\hline 14 & Cameroon & 0.82 & $3.41^{*}$ & 0.17 & $7.18^{*}$ & 504 \\
\hline 15 & Chile & 1.13 & $20.56^{*}$ & 0.26 & $12.38^{*}$ & 481 \\
\hline 16 & Dominican Republic & 0.32 & 0.83 & $3.68^{*}$ & $22.53^{*}$ & 332 \\
\hline 17 & Ecuador & 1.39 & $5.87^{*}$ & 0.46 & 1.14 & 548 \\
\hline 18 & El Salvador & 0.54 & 2.15 & 1.60 & $15.94^{*}$ & 387 \\
\hline 19 & Georgia & 0.88 & $3.26^{*}$ & 0.06 & $5.25^{*}$ & 541 \\
\hline 20 & Ghana & 0.63 & $4.40^{*}$ & 1.54 & $20.97^{*}$ & 379 \\
\hline 21 & Honduras & 0.91 & $4.51^{*}$ & 0.05 & $6.56^{*}$ & 230 \\
\hline 22 & India & 0.92 & 1.28 & 0.01 & 1.76 & 1,241 \\
\hline 23 & Indonesia & 1.24 & $9.70^{*}$ & 0.36 & $3.70^{*}$ & 758 \\
\hline 24 & Kosovo & 1.03 & $6.15^{*}$ & 0.01 & $5.46^{*}$ & 521 \\
\hline 25 & Kyrgyz Republic & 1.81 & $7.54^{*}$ & 1.50 & 0.09 & 564 \\
\hline 26 & Lao People's Dem. Rep. & 0.39 & 0.50 & 1.21 & $8.44^{*}$ & 627 \\
\hline
\end{tabular}

NOTE: Developed countries are those with gross national income per capita greater than $\$ 12,000$ USD in 2010 . The chi-square statistics correspond to the likelihood ratio tests for the null hypotheses that $\rho=0, \rho=1$, or $\rho=2$. ${ }^{*}$ indicates statistical significance at the 10 percent level. No. obs., number of observations. 


\section{Table 2B, cont'd}

\section{Relative Risk Aversion by Country (Developing Countries)}

\begin{tabular}{|c|c|c|c|c|c|c|}
\hline & Country & $\rho$ & $\begin{array}{c}\chi^{2} \\
H_{0}: \rho=0\end{array}$ & $\begin{array}{c}\chi^{2} \\
H_{0}: \rho=1\end{array}$ & $\begin{array}{c}\chi^{2} \\
H_{0}: \rho=2\end{array}$ & No. obs. \\
\hline 27 & Lithuania & 1.23 & $18.51^{*}$ & 0.64 & $7.27^{*}$ & 452 \\
\hline 28 & Macedonia & 1.34 & $15.43^{*}$ & 1.00 & $3.71 *$ & 563 \\
\hline 29 & Madagascar & 0.72 & 2.33 & 0.36 & $7.45^{*}$ & 618 \\
\hline 30 & Malaysia & 1.93 & 1.71 & 0.40 & 0.00 & 497 \\
\hline 31 & Mexico & 0.78 & 1.22 & 0.10 & $3.02^{*}$ & 469 \\
\hline 32 & Moldova & 1.19 & $8.58^{*}$ & 0.23 & $3.91 *$ & 545 \\
\hline 33 & Montenegro & 2.10 & $11.38^{*}$ & $3.14^{*}$ & 0.03 & 322 \\
\hline 34 & Mozambique & 1.11 & $19.22^{*}$ & 0.19 & $12.38^{*}$ & 486 \\
\hline 35 & Myanmar & 1.01 & $10.72^{*}$ & 0.00 & $10.28^{*}$ & 749 \\
\hline 36 & Panama & 0.18 & 0.25 & $4.83^{*}$ & $23.92^{*}$ & 476 \\
\hline 37 & Paraguay & 0.47 & 0.23 & 0.29 & 2.39 & 480 \\
\hline 38 & Peru & 1.44 & $6.72^{*}$ & 0.63 & 1.01 & 359 \\
\hline 39 & Russia & 0.65 & $5.02^{*}$ & 1.46 & $21.69^{*}$ & 1,000 \\
\hline 40 & Senegal & 1.89 & $4.65^{*}$ & 1.03 & 0.02 & 407 \\
\hline 41 & Serbia & 0.27 & 0.35 & 2.60 & $14.54^{*}$ & 815 \\
\hline 42 & South Africa & 1.29 & $36.15^{*}$ & 1.79 & $11.13^{*}$ & 458 \\
\hline 43 & Sri Lanka & 0.68 & $4.23^{*}$ & 0.91 & $15.72^{*}$ & 692 \\
\hline 44 & Tajikistan & 1.19 & $4.96^{*}$ & 0.12 & 2.33 & 523 \\
\hline 45 & Tanzania & 1.26 & $7.11^{*}$ & 0.30 & 2.46 & 395 \\
\hline 46 & Uganda & 0.67 & $20.24^{*}$ & $5.04^{*}$ & $80.79^{*}$ & 497 \\
\hline 47 & Ukraine & 0.44 & 0.44 & 0.69 & $5.41^{*}$ & 564 \\
\hline 48 & Uruguay & 0.90 & $11.74^{*}$ & 0.15 & $17.59^{*}$ & 485 \\
\hline 49 & Uzbekistan & 2.96 & $14.59^{*}$ & $6.40^{*}$ & 1.54 & 551 \\
\hline 50 & Venezuela & 2.08 & $11.13^{*}$ & $2.99 *$ & 0.01 & 452 \\
\hline 51 & Vietnam & 1.15 & $18.74^{*}$ & 0.32 & $10.18^{*}$ & 558 \\
\hline 52 & Zimbabwe & 0.04 & 0.00 & 0.93 & $3.88^{*}$ & 518 \\
\hline
\end{tabular}

NOTE: Developed countries are those with gross national income per capita greater than $\$ 12,000$ USD in 2010. The chi-square statistics correspond to the likelihood ratio tests for the null hypotheses that $\rho=0, \rho=1$, or $\rho=2$. * indicates statistical significance at the 10 percent level. No. obs., number of observations. 


\section{Figure 1}

\section{Relative Risk Aversion Among Developed Countries}

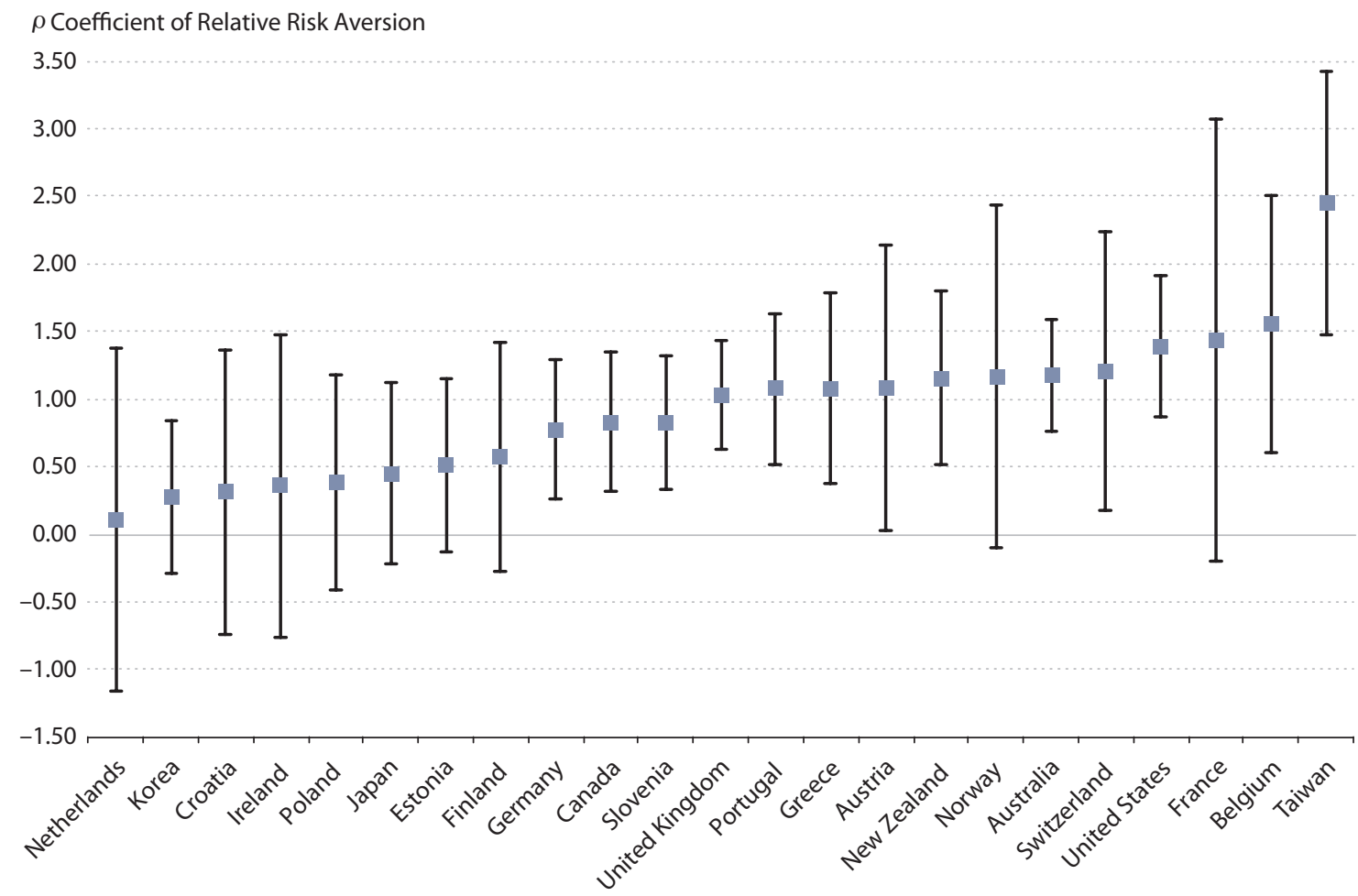

NOTE: The squares indicate point estimates. The vertical lines represent the 90 percent confidence intervals.

\section{CONCLUSION}

The financial economics literature has made a significant effort to find adequate measures of risk aversion, but in general has focused on providing estimates for a limited set of mostly developed countries. Szpiro and Outreville (1988), for example, study 31 countries, including only 11 developing countries. Their methodology uses insurance data and primarily tests the hypothesis of constant relative risk aversion, which cannot be rejected for the majority of countries considered. In this article, we modify the methodology of Layard, Mayraz, and Nickell (2008) and Gandelman and Hernández-Murillo (2013) to estimate the coefficient of relative risk aversion using subjective well-being data for 75 countries, including 52 developing countries.

Our individual country estimates range from 0 to 3 , with an average of 0.98 . Wald tests for the vast majority of countries indicate that the coefficient of relative risk aversion is smaller than 2 and largely in the vicinity of 1 . These estimates of relative risk aversion are smaller than those found for individual countries by Szpiro and Outreville (1988); their estimates range between 1 and 5, with an average of 2.89. Our estimates are close to the results of Layard, Mayraz, and Nickell (2008) and Gandelman and Hernández-Murillo (2013). 


\section{Figure 2}

\section{Relative Risk Among Developing Countries}

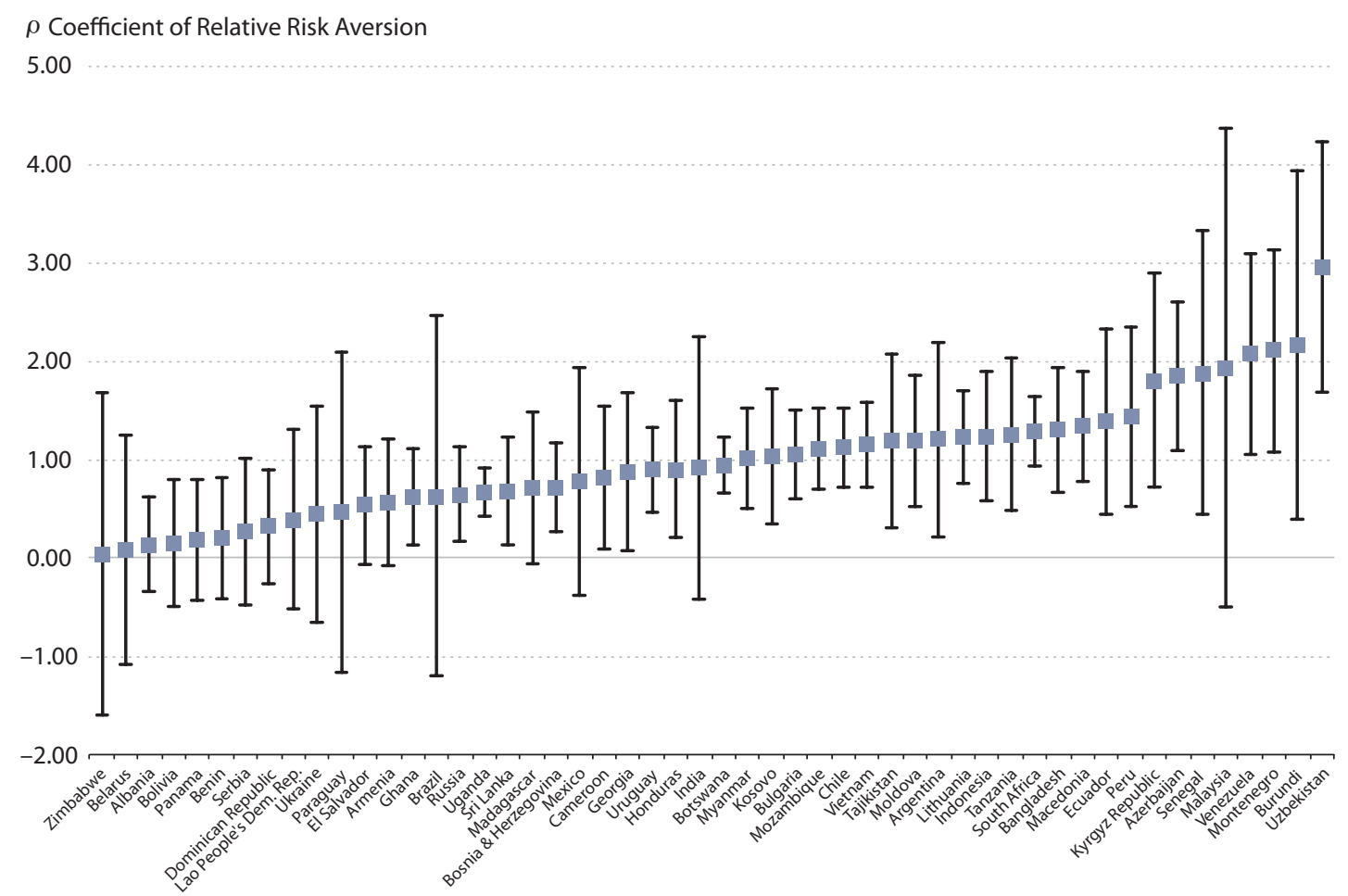

NOTE: The squares indicate point estimates. The vertical lines represent the 90 percent confidence intervals.

Many economic models, including dynamic general stochastic equilibrium models, require estimates of key parameters, including the coefficient of relative risk aversion. Our findings support the use of the log form for the utility function in such exercises, which corresponds to a coefficient of unity for the coefficient of relative risk aversion. Our results also inform the construction of models in which it is important to allow for differing parameterizations for developed and developing countries. 


\section{Figure 3}

\section{Kernel Density Estimates of the $\rho$ Distribution}

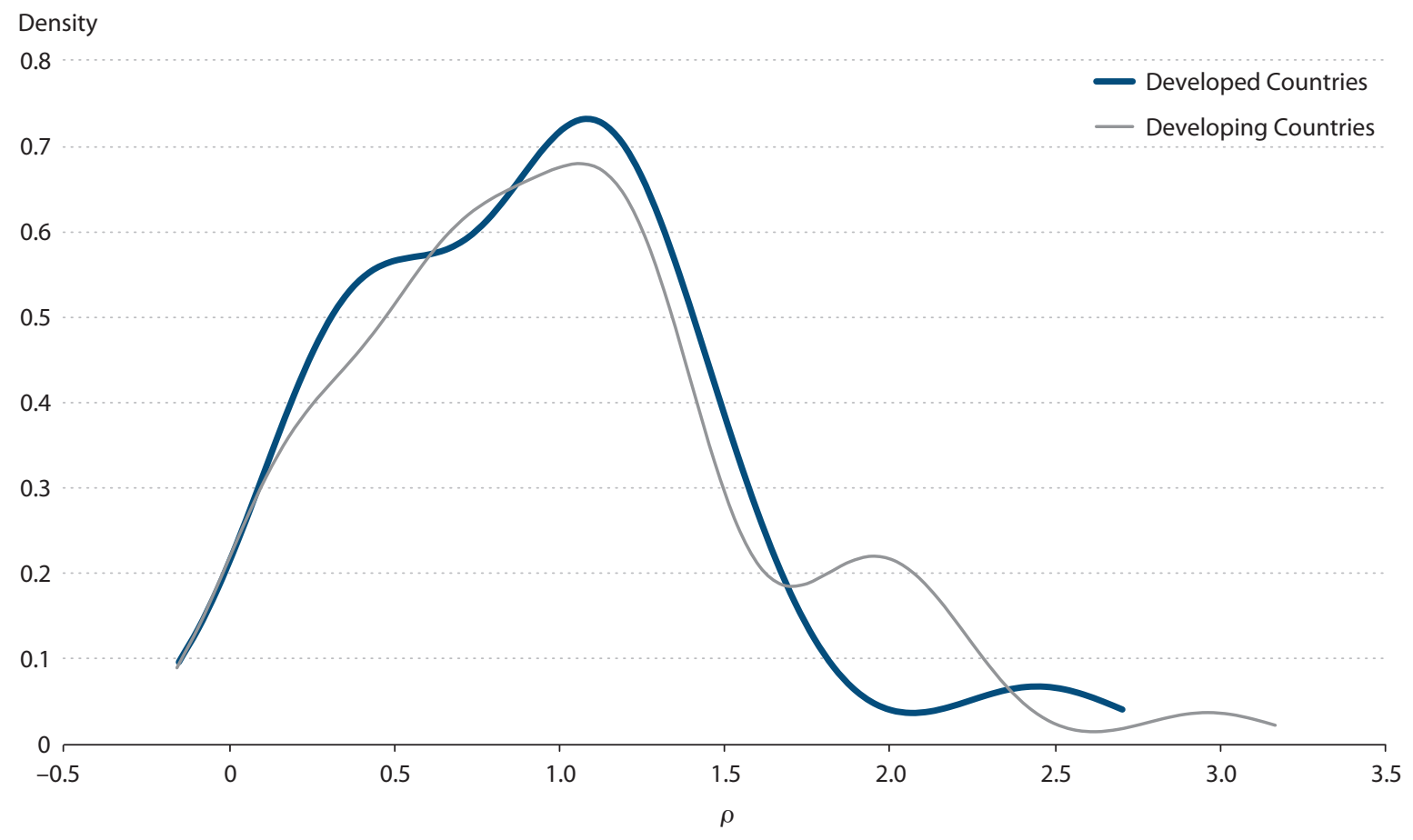

\section{NOTES}

1 See Chetty (2006); Campo et al. (2011); Friend and Blume (1975); Gandelman and Hernández-Murillo (2013); Garcia, Lugar, and Renault (2003); Gordon and St-Amour (2004); Hansen and Singleton (1983); Kapteyn and Teppa (2011); Layard, Mayraz, and Nickell (2008); Mankiw (1985); Szpiro (1986); and Weber (1975).

2 For example, the CRRA utility function implies stationary risk premia and interest rates even in the presence of long-run economic growth. See Mehra and Prescott (2008) for additional discussions on the implications on the equity premium.

3 See Kocherlakota (1990) for a criticism of the Epstein-Zin approach and Kocherlakota (1996) for a more in-depth analysis and its implication for the equity premium puzzle.

4 For an exception, see Gandelman and Hernández-Murillo (2013), who estimate measures of risk aversion for groups of countries classified by income level.

5 The log utility function has the property that in a trade-off between present and future consumption, the income and substitution effects, in response to changes in the interest rate, exactly offset.

6 Household income data are reported in 29 brackets. We use the midpoint of the brackets as the measure of income, and for the top bracket we use a value equal to twice the previous midpoint value. In our estimations, income is expressed as deviations from the country average. This normalization facilitates the numerical estimation and has no effect on the estimates of the risk aversion coefficient.

7 The authors' income definitions are based on the 2010 World Bank income classification groups. The current year's groupings and more information about the classification process can be found on the World Bank's website (http://data.worldbank.org/news/2015-country-classifications). 
8 The reported income means differ from 100 percent because we trimmed outlier observations from the sample.

9 For further discussion, see Clark, Frijters, and Shields (2008) and the references therein.

${ }^{10}$ For this discussion we follow loosely the notation of MacKerron (2012).

${ }^{11}$ The coefficients are identified up to an affine transformation of the utility function in equation (1).

12 To be sure that our results are not affected by outliers in the income reports, we run a regression of the log of relative income on individual controls and trim observations in the bottom and top 5 percent of the distribution of residuals, as in Layard, Mayraz, and Nickell (2008).

${ }^{13}$ We implement the estimation with Stata version 12.0 using a wrapper function for the built-in GMM procedure for which we provide the explicit derivatives of the moment conditions. The programs are available upon request from the authors.

${ }^{14}$ We eliminate from the sample developed and developing countries for which the estimation procedure does not find a value for $\rho$.

\section{REFERENCES}

Campo, Sandra; Guerre, Emmanuel; Perrigne, Isabelle; and Vuong, Quang. "Semiparametric Estimation of First-Price Auctions with Risk-Averse Bidders." Review of Economic Studies, January 2011, 78(1), pp. 112-47; http://restud.oxfordjournals.org/content/78/1/112.long.

Chetty, Raj. "A New Method of Estimating Risk Aversion." American Economic Review, December 2006, 96(5), pp. 1821-34; http://pubs.aeaweb.org/doi/pdfplus/10.1257/aer.96.5.1821.

Clark, Andrew E.; Frijters, Paul and Shields, Michael A. "Relative Income, Happiness, and Utility: An Explanation for the Easterlin Paradox and Other Puzzles." Journal of Economic Literature, March 2008, 46(1), pp. 95-144; http://www.jstor.org/stable/27646948.

Epstein, Larry G. and Zin, Stanley E. "Substitution, Risk Aversion, and the Temporal Behavior of Consumption Growth and Asset Returns: A Theoretical Framework." Econometrica, July 1989, 57(4), pp. 937-69; http://www.jstor.org/stable/1913778.

Epstein, Larry G. and Zin, Stanley E. "Substitution, Risk Aversion, and the Temporal Behavior of Consumption Growth and Asset Returns: An Empirical Analysis." Journal of Political Economy, April 1991, 99(2), pp. 263-86; http://www.jstor.org/stable/2937681.

Ferrer-i-Carbonell, Ada and Frijters, Paul. "How Important Is Methodology for the Estimates of the Determinants of Happiness?" Economic Journal, July 2004, 114(497), pp. 641-59; http://www.jstor.org/stable/3590299.

Friend, Irwin and Blume, Marshall E. "The Demand for Risky Assets." American Economic Review, December 1975, 65(5), pp. 900-22; http://www.jstor.org/stable/1806628.

Gandelman, Néstor and Porzecanski, Rafael. “Happiness Inequality: How Much Is Reasonable?" Social Indicators Research, January 2013, 110(1), pp. 257-69; http://link.springer.com/article/10.1007/s11205-011-9929-z.

Gandelman, Néstor and Hernández-Murillo, Rubén. “What Do Happiness and Health Satisfaction Data Tell Us About Relative Risk Aversion?" Journal of Economic Psychology, August 2013, 39, pp. 301-12; http://www.sciencedirect.com/science/article/pii/S0167487013001116.

Geweke, John. “A Note on Some Limitations of CRRA Utility." Economics Letters, June 2001, 71(3), pp. 341-45; http://www.sciencedirect.com/science/article/pii/S0165176501003913.

Garcia, René; Luger, Richard and Renault, Eric. “Empirical Assessment of an Intertemporal Option Pricing Model with Latent Variables." Journal of Econometrics, September-October 2003, 116(1-2), pp. 49-83;

http://www.sciencedirect.com/science/article/pii/S0304407603001039.

Gordon, Stephen and St-Amour, Pascal. "Asset Returns and State-Dependent Risk Preferences." Journal of Business and Economic Statistics, July 2004, 22(3), pp. 241-52; http://www.jstor.org/stable/1392594.

Hall, Robert. "Intertemporal Substitution in Consumption." Journal of Political Economy, April 1988, 96(2), pp. 339-57; http://www.jstor.org/stable/1833112. 


\section{Gandelman and Hernández-Murillo}

Hansen, Lars Peter and Singleton, Kenneth J. "Generalized Instrumental Variables Estimation of Nonlinear Rational Expectations Models." Econometrica, September 1982, 50(5), pp. 1269-86; http://www.jstor.org/stable/1911873.

Hansen, Lars Peter and Singleton, Kenneth J. "Stochastic Consumption, Risk Aversion and the Temporal Behavior of Asset Returns." Journal of Political Economy, April 1983, 91(2), pp. 249-65; http://www.jstor.org/stable/1832056.

Kapteyn, Arie and Teppa, Federica. "Subjective Measures of Risk Aversion, Fixed Costs, and Portfolio Choice." Journal of Economic Psychology, August 2011, 32(4), pp. 564-80; http://www.sciencedirect.com/science/article/pii/S0167487011000602.

Kocherlakota, Narayana R. "Disentangling the Coefficient of Relative Risk Aversion from the Elasticity of Intertemporal Substitution: An Irrelevance Result." Journal of Finance, March 1990, 45(1), pp. 175-90; http://www.jstor.org/stable/2328815.

Kocherlakota, Narayana R. “The Equity Premium: It's Still a Puzzle.” Journal of Economic Literature, March 1996, 34(1), pp. 42-71; http://www.jstor.org/stable/2729409.

Layard, Richard; Mayraz, Guy and Nickell, Stephen John. "The Marginal Utility of Income." Journal of Public Economics, August 2008, 92(8-9), pp. 1846-57; http://www.sciencedirect.com/science/article/pii/S0047272708000248.

MacKerron, George. “Happiness Economics from 35,000 Feet." Journal of Economic Surveys, September 2012, 26(4), pp. 705-35; http://onlinelibrary.wiley.com/doi/10.1111/j.1467-6419.2010.00672.x/full.

Mankiw, N. Gregory. "Consumer Durables and the Real Interest Rate." Review of Economics and Statistics, 1985, 67(3), pp. 353-62.

Mehra, Rajnish; and Prescott, Edward C. "The Equity Premium: ABCs," in Mehra Rajnish, ed., Handbook of the Equity Risk Premium. Chap. 1. Amsterdam: Elsevier, 2008.

Neely, Christopher J.; Roy, Amlan and Whiteman, Charles H. "Risk Aversion Versus Intertemporal Substitution: A Case Study of Identification Failure in the Intertemporal Consumption Capital Asset Pricing Model." Journal of Business \& Economic Statistics, October 2001, 19(4), pp. 395-403. http://www.tandfonline.com/doi/abs/10.1198/07350010152596646\#.VKsfi_PnaUk.

Stewart, Kenneth G. “The Optimal Construction of Instruments in Nonlinear Regression: Implications for GMM Inference." Econometrics Working Paper No. EWP1107, University of Victoria, May 2011; http://www.uvic.ca/socialsciences/economics/assets/docs/econometrics/ewp1107.pdf.

Szpiro, George G. "Relative Risk Aversion Around the World." Economics Letters, 1986, 20(1), pp. 19-21; http://www.sciencedirect.com/science/article/pii/0165176586900728.

Szpiro, George G. and Outreville, Jean-François. "Relative Risk Aversion Around the World: Further Results." Journal of Banking and Finance, 1988, 6(Supplement 1), pp. 127-28; http://www.sciencedirect.com/science/article/pii/0378426688900635.

Weber, Warren E. "Interest Rates, Inflation, and Consumer Expenditures." American Economic Review, 1975, 65(5), pp. 843-58; http://www.jstor.org/stable/1806624. 